\title{
Monitoring of temperature variation in manufacturing process of centrifugally cast pipe using infrared thermography
}

\author{
by Hyunchul Jung ${ }^{*}$, Seolhee $\mathrm{Yi}^{*}$, Kiyoul Kim*, Kyengwoon Kim*, Hongki Choi**, and Kyeongsuk Kim \\ * Chosun University, 61452, 309 Pilmun-daero, Dong-gu, Gwangju, South Korea, hyunchul.jung@chosun.ac.kr \\ ** TMC Co., Ltd., 202, Korea Carbon Fusion Technology Institute, 67, Yusang-ro, Deokjin-gu, Jeonju-si, Jeonbuk, \\ South Korea, tenkim@tmcltd.co.kr
}

\begin{abstract}
In many manufacturing processes, the monitoring of the temperature variation is needed. Manufacturing of a centrifugally cast pipe is processed when the molten metal is poured into the rotating mould with high speed and the thin layer is formed at the inner surface of the mould. Before the rotating mould is heated, the failure rate of the produced pipe is higher than after the process was done several times. In this paper, using the infrared thermography, the temperature variation of the case of centrifugal casting mould during the manufacturing process is monitored, recorded and analysed.
\end{abstract}

\section{Introduction (Arial, 9pt, bold)}

In many manufacturing processes, the monitoring of the temperature variation is needed to verify whether each operation stage is working normally or not. Manufacturing of a centrifugally cast pipe is processed when the molten metal is poured into the rotating mould with high speed and the thin layer is formed at the inner surface of the mould [1,2]. In the beginning stage, the failure rate of the produced pipe is higher because the hot molten metal is poured in the rotating mould with low temperature. After the rotating mould is heated during the manufacturing process, the failure rate of the pipe is decreased. Therefore the temperature monitoring in the manufacturing of a centrifugally cast pipe is necessary. Infrared thermography is used to monitor and analyse the status and abnormality of a structure due to the temperature change $[3,4]$. In this paper, the temperature monitoring is provided by the passive infrared thermography. With the infrared thermography, the temperature variation of the centrifugal casting mould during the manufacturing period is recorded. The analysis results related to the failure rate is discussed.

\section{Background}

The fundamental of the centrifugal casting for manufacturing pipe horizontally and the theory of the passive infrared thermography are introduced.

\subsection{Centrifugal casting}

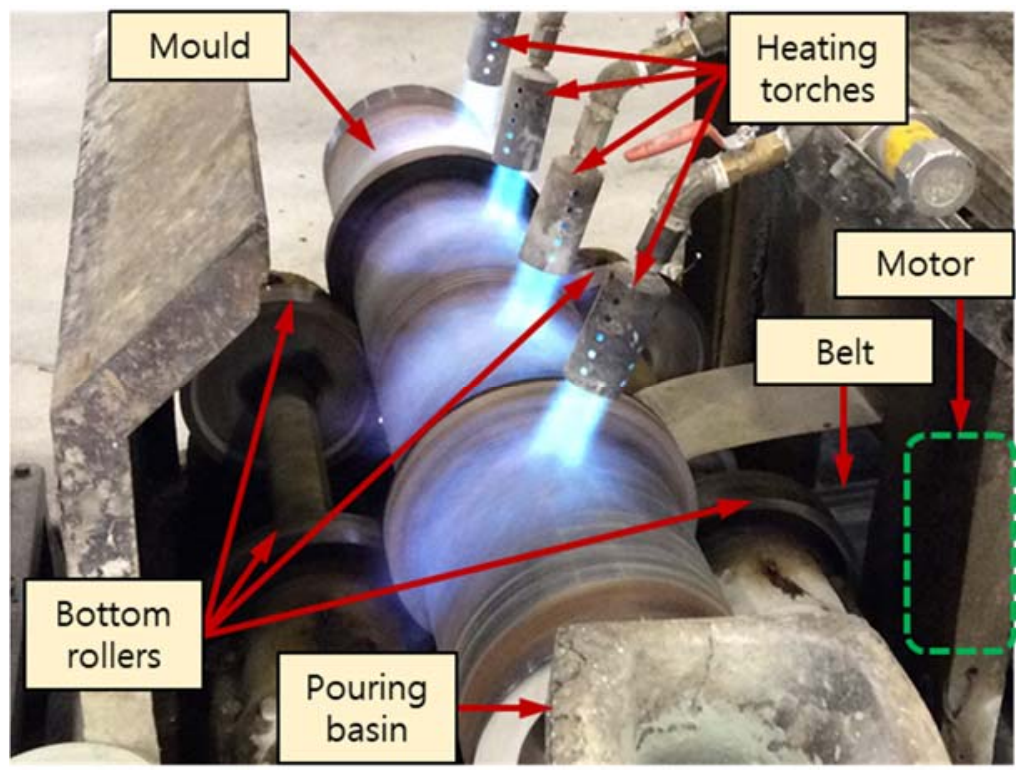

Fig. 1. Arrangement of centrifugal casting to produce pipe 
As shown in figure 1, centrifugal casting system consists of motor, rotating rollers, pouring basin, mould, and heating torches. A motor is used to rotate a mould laid on the bottom rollers at $300 \sim 3,000 \mathrm{rpm}$. The molten metal is poured into a mould pass through a pouring basin. When the hot molten metal is poured in a mould, the difference of temperature between the molten metal and a mould. If this temperature difference is greater than the proper temperature, then some kinds of failure are occurred. In this case, the several heating torches are used for heating a mould. These torches are typically used in the morning or winter season. When the molten metal is poured in a mould rotating with high speed, a pipe with the thickness required in manufacturing process is produced. Centrifugal casting is used to produce the cylindrical component only.

\subsection{Passive infrared thermography}

There exists two types of infrared thermography, passive and active [3, 4]. As shown in figure 2(a), in passive infrared thermography, small amount of infrared energy emitted from an object itself is detected by IR camera. In active infrared thermography, an object is stimulated by a mechanical, electromagnetic, optical, or any other method and the infrared energy emitted from an object is detected by IR camera. Figure 2(b) shows the active infrared thermography setup. Generally, the detection of an abnormality, such as stress concentration, crack, void, delamination, disband, etc. is dealt with an active infrared thermography. While passive infrared thermography is typically used to monitor the temperature variation of a target and to find an abnormal temperature point or to analyse a problem produced on a target using the temperature difference.

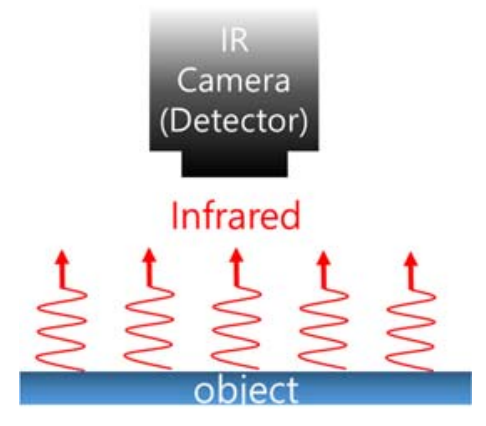

(a)

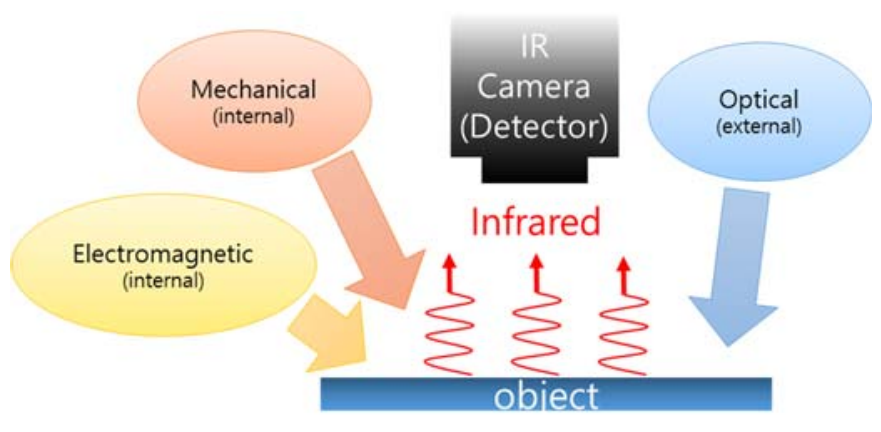

(b)

Fig. 2. (a) Passive infrared thermography setup and (b) Active infrared thermography setup

\section{Experiment}

A centrifugal casting system for producing pipe was monitored using IR camera system (SC-5400, FLIR). Table 1 shows the specification of IR camera system. As shown in figure 3, IR camera system installed on a tripod was placed in front of the centrifugal casting system. The material of a pipe is $27 \mathrm{Cr}-\mathrm{Fe}$ Bal. with small amount of Carbon and other elements. This pipe is used for a transfer pipe of the concrete pump car. The length, diameter, and thickness of a pipe is $1,110 \mathrm{~mm}, 130 \mathrm{~mm}$, and $3 \mathrm{~mm}$, respectively. The rotating speed is $750 \mathrm{rpm}$. The temperature in the working area is about $44^{\circ} \mathrm{C}$.

The IR camera begin the recording before the molten metal was poured in a centrifugal casting mould. The recording was stopped after a produced pipe was pulled out from a mould. It takes about 2.5 min. During the recording process, stoppers which is used to stop the molten metal from leaving a mould are removed and a produced pipe is pulled out from a mould by workers. The emissivity of a mould is 0.85 and that of a pipe is 0.10 .

Table 1. Specification of IR camera system

\begin{tabular}{|c|c|}
\hline Model & SC 5400 \\
\hline NETD & $<20 \mathrm{mK}$ \\
\hline Sensor type & $\operatorname{InSb}(3-5 \mu \mathrm{m})$ \\
\hline Camera calibration range & $-20^{\circ} \mathrm{C}$ to $1,500{ }^{\circ} \mathrm{C}$ \\
\hline Pixel resolution & $320 \times 256,14 \mathrm{bits}$ \\
\hline Digital full frame rate & Max, $380 \mathrm{~Hz}$ \\
\hline
\end{tabular}




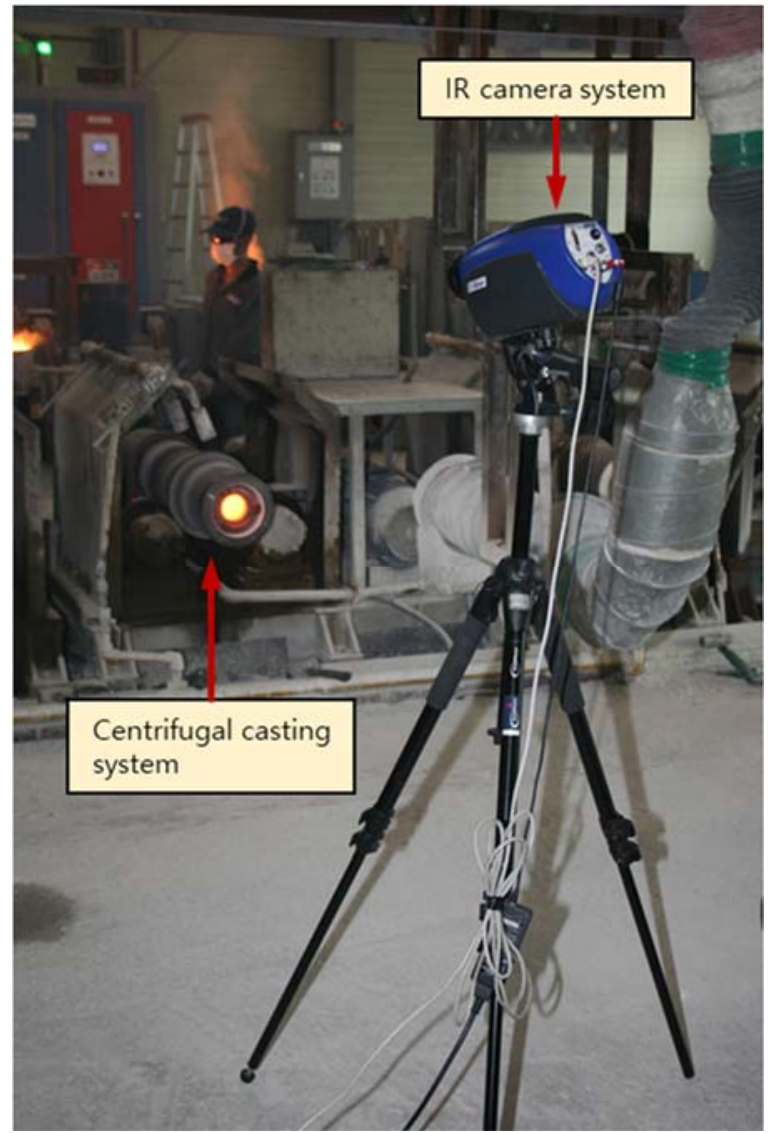

Fig. 3. Experimental setup for monitoring temperature variation

\section{Results and discussion}

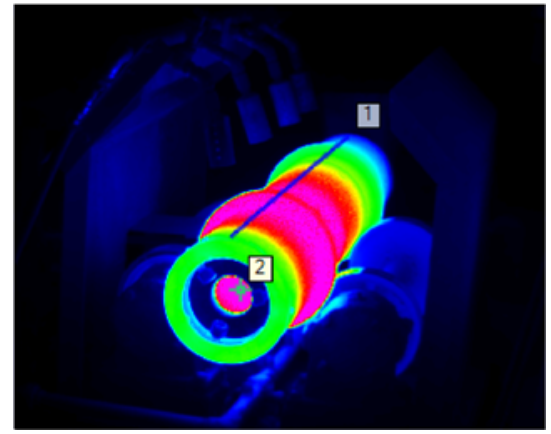

(a)

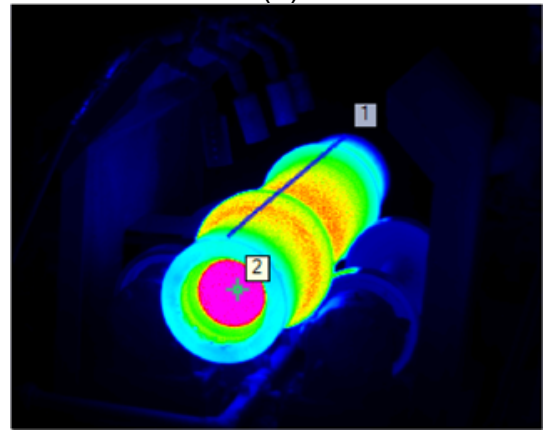

(d)

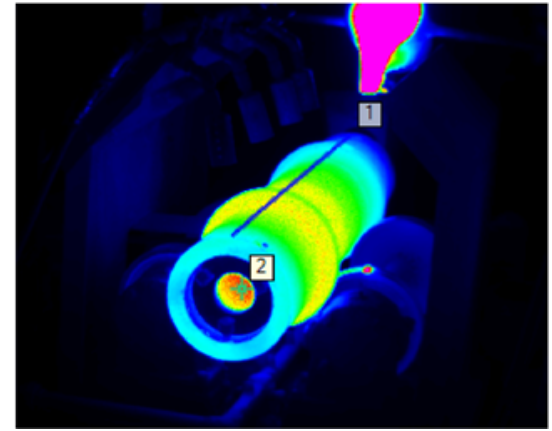

(b)

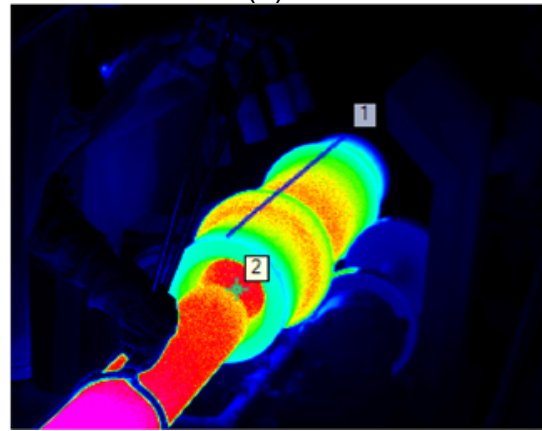

(e)

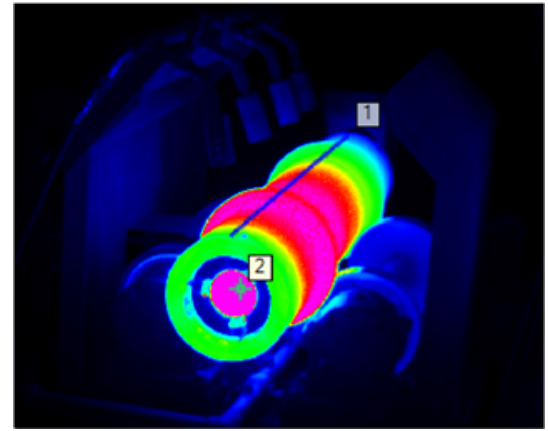

(c)

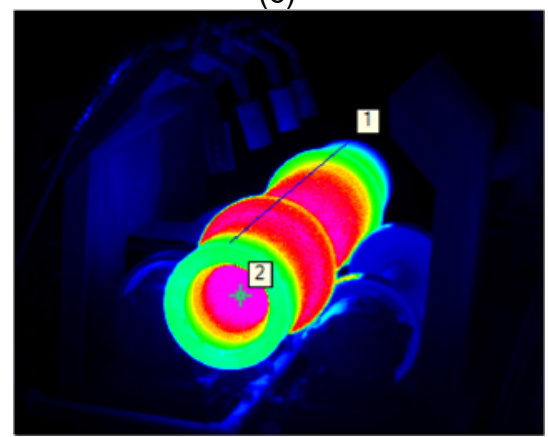

(f)

Fig. 4. IR thermographic images, (a) before pouring molten metal (50 frame), (b) pouring molten metal (130 frame), (c) after pouring molten metal (200 frame), (d) after removing stopper (1620 frame), (e) removing pipe (1796 frame), and $(f)$ after removing pipe (1850 frame) 
Figure 4 shows IR thermographic images for each state of a centrifugal casting system. In figure 4 , the profile line 1 is used to monitor the temperature variation of the surface of a mould and the point 2 is used to monitor that of the inside of a mould. Figure 5 shows the result of the temperature variation of the point 2 . In figure 5 , frame means the frame recorded by IR camera

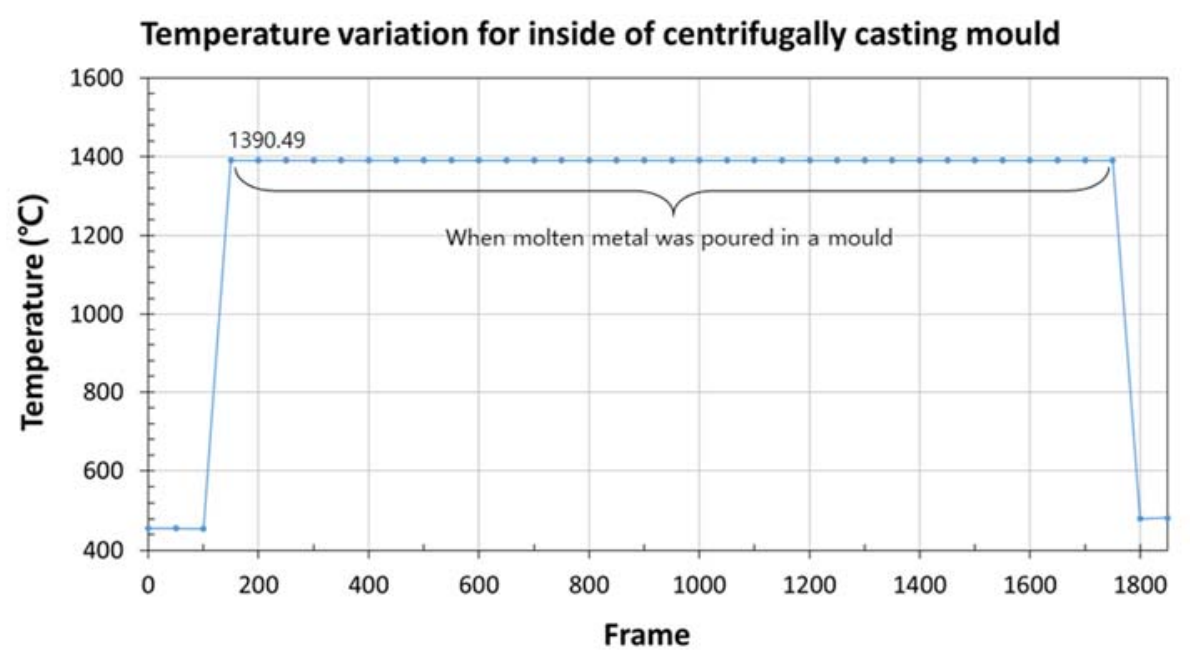

Fig. 5. Result of the temperature variation of point 2 for inside of centrifugally casting mould

The temperature of the inside of a mould before the molten metal is poured in a mould is around $455^{\circ} \mathrm{C}$. After the molten metal was poured, the temperature is $1,390.49{ }^{\circ} \mathrm{C}$. After a produced pipe was pulled out from a mould, the temperature is around $481^{\circ} \mathrm{C}$. The temperature difference between before the molten metal is poured in a mould and after a pipe was pulled out from a mould is $26^{\circ} \mathrm{C}$. However, there is an error on the temperature value because the temperature is varied due to the emissivity of material. In this experiment, the emissivity of the cast iron covered the mould releasing agent $(0.85)$ is used for a mould and that of the chromium (0.10) is used for a pipe. Because the temperature difference affect to the process of the centrifugal casting, when a pipe is produced in the winter season or early in the morning, the failure rate is higher than when the process is done in the summer season or in the afternoon.

Figure 6 shows the result of the temperature variation for the surface of a mould. In figure 6 , position means the pixels on the profile line. Figure 7 shows the temperature variation of $A$ and $B$ position in figure 6 .

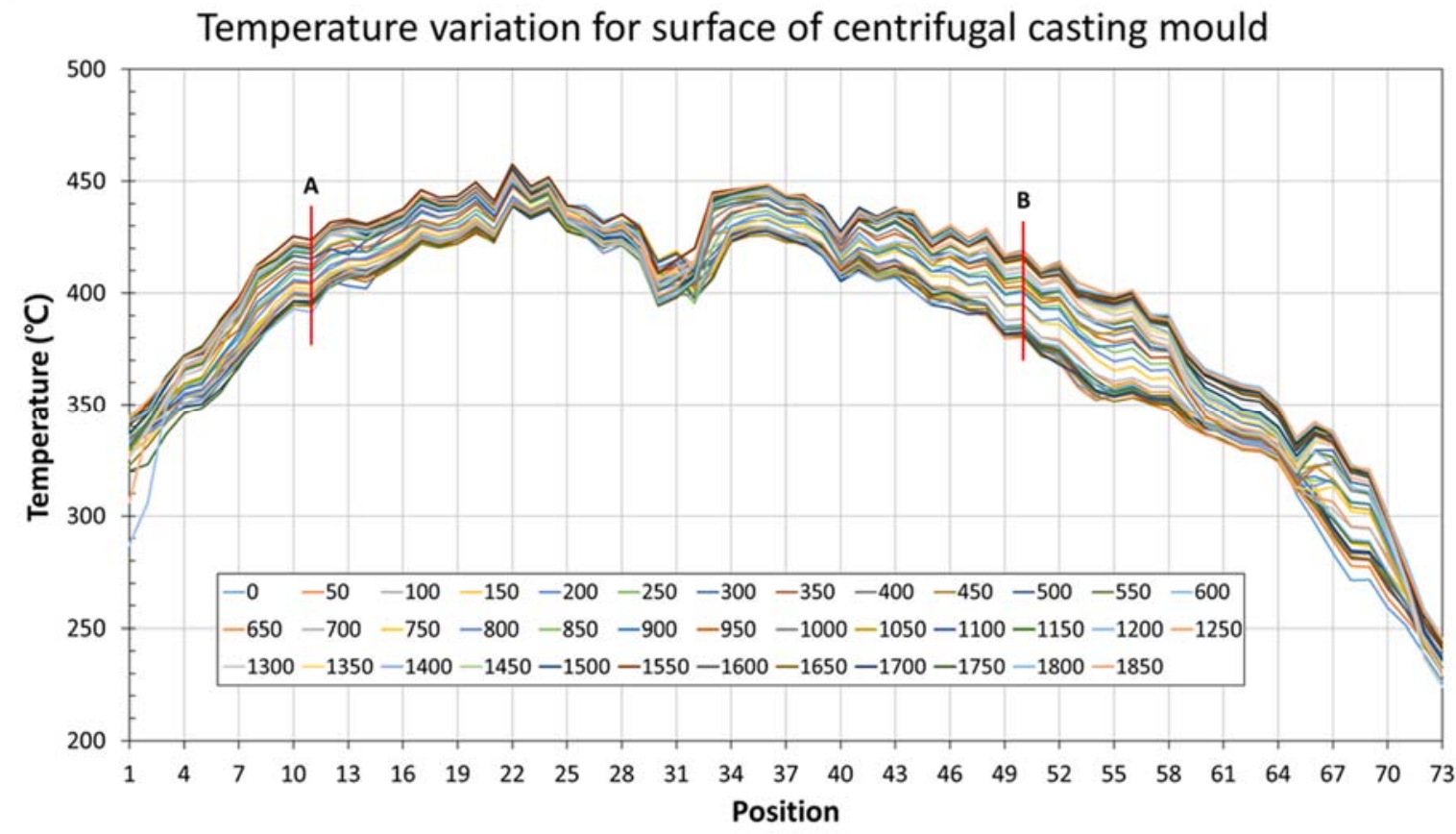

Fig. 6. Result of the temperature variation of profile line 1 for the surface of a mould according to the frame 


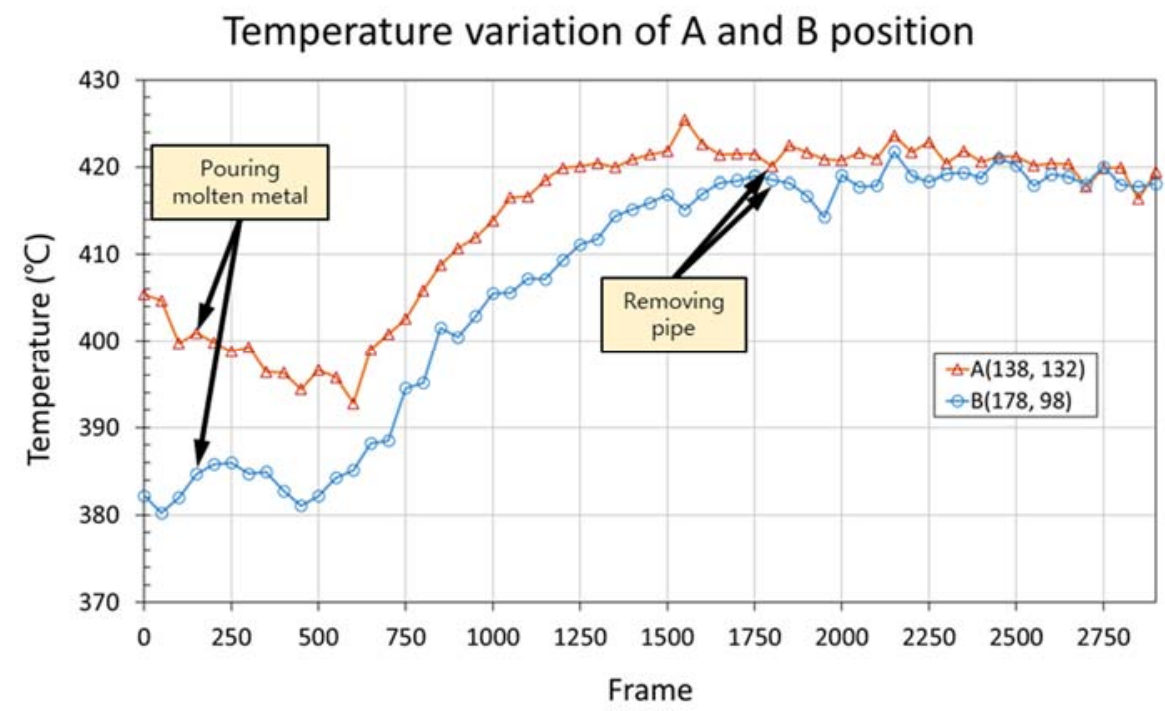

Fig. 7. Result of the temperature variation of $A$ and $B$ position in figure 6

As shown in figure 7 , the molten metal was poured in a mould at 150 frame and a produced pipe was pulled out from a mould at 1800 frame. The coordination of position $A$ and $B$ is $(138,132)$ and $(178,98)$, respectively. Until 600 frame, the temperature variation bandwidth of the surface of a mould is small. The temperature of the surface of a mould is increased until 1800 frame when a produced pipe is pulled out from a mould. After 1800 frame, the temperature variation is very small.

In the manufacturing process for producing a centrifugal casting pipe, the temperature in a mould before pouring the molten metal in a mould should be $450{ }^{\circ} \mathrm{C}$ at least for decreasing the failure rate. The temperature variation for the surface of a mould between before and after pouring the molten metal in a mould should be maintained to do not exceed over $45^{\circ} \mathrm{C}$.

\section{Conclusion}

In this paper, the temperature variation of a centrifugal casting system was monitored by using IR camera system. From the results, it is concluded that 1) the temperature of a pipe in a mould until a produced pipe is pulled out from a mould is constant as $1390.49{ }^{\circ} \mathrm{C}, 2$ ) the temperature difference between the starting stage and the ending stage is about $26{ }^{\circ} \mathrm{C}, 3$ ) the temperature of a mould after removing a produced pipe is maintained constant, and 4) for decreasing the failure rate of the produced pipes, the temperature of the molten metal should be $450{ }^{\circ} \mathrm{C}$ at least. Also, it was confirmed that an error can be included in the results because of the emissivity of a target. The accurate emissivity of a target should be measured and used.

\section{Acknowledgement}

This research was supported by the Ministry of Trade, Industry \& Energy(MOTIE), Korea Institute for Advancement of Technology(KIAT) through the Local Public Agency Support Program (P0000204, 2017).

\section{REFERENCES}

[1] Swift K. G., Booker J. D., "Manufacturing Process Selection Handbook". pp. 75-78, Butterworth-Heinemann, New York, 2013.

[2] Campbel J., "Complete Casting Handbook, Second Edition: Metal Casting Processes, Metallurgy, Techniques and Design", Butterworth-Heinemann, New York, 2015.

[3] Maldague X., "Theory and Practice of Infrared Technology for Nondestructive Testing". pp. 1-11, pp. 496-527, John Wiley \& Sons, New York, 2001.

[4] Czichos H., "Handbook of Technical Diagnostics: Fundamentals and Application to Structures and System". pp. 175-220, Springer, New York, 2013. 